\title{
Golden Eagles Nesting in Saskatchewan
}

by Richard W. Fyfe, Saskatchewan Museum of Natural History

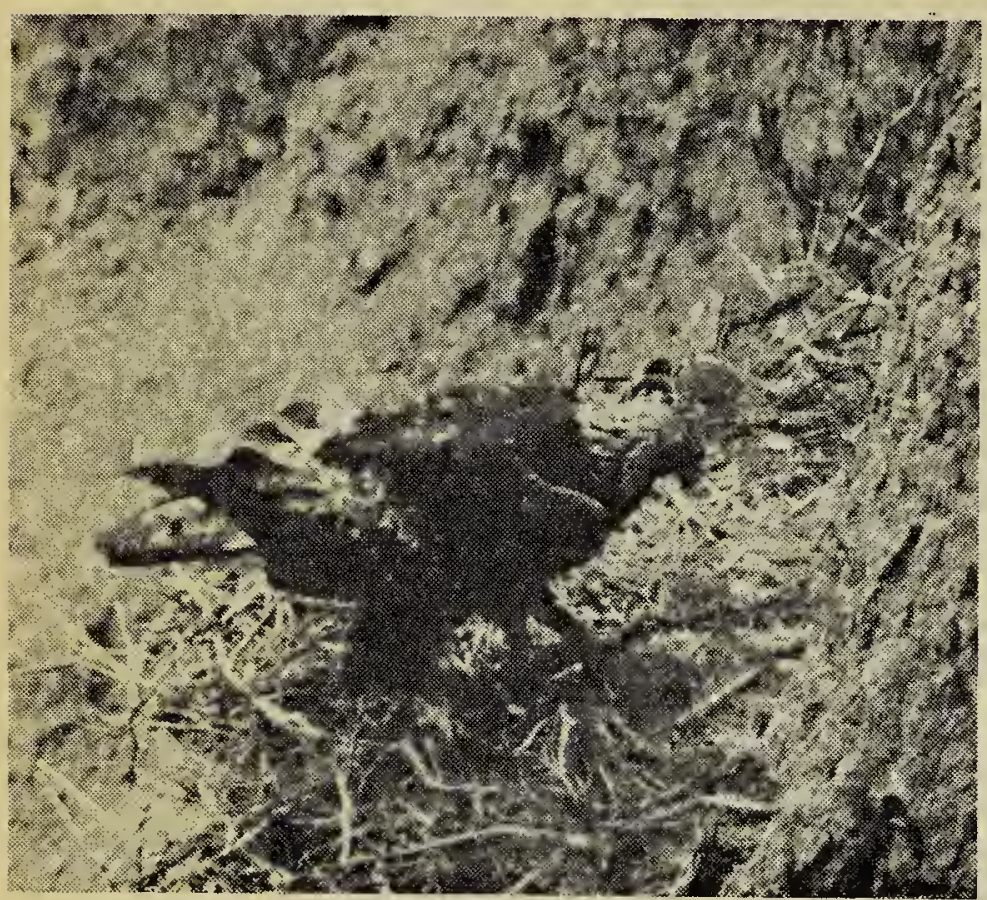

Photo by R.W. Fyfe

Fig. 1. Adult Golden Eagle arriving with food for eaglet.

There are two previous published repcrts of Golden Eagles (Aquila chrysaetos) nesting in this province. The first report was that of Jcseph Burr Tyrrell, 1892 (Annual Report Geological Survey cf Canada VIII 1895); this was followed by D. Santy's report (Blue Jay, Vol. XVI, Dec. 1958) some 66 years later. As a direct result of Mr. Santy's report we made an attempt to locate and photograph these birds during the spring of 1959.

On May 19, Mr. Santy, Ralph Ostoforoff and I found an active nest on the bank of the South Saskatchewan River about three miles from the nest of the previous year. The nest was located on the north bank of the Snakebite Coulee on a sharp cutbank estimated to be about 300 feet high, the nest itself about 50 feet below the top of the cliff. On May 29, a return visit was made and a photography blind set up $\dot{ }_{i} i$ about 120 feet above and to the northwest of the nest. Although this blind was used on four separate occasions for a total of 79 hours, only one photo of the adult bird was taken (see Fig. 1).

During the week of June 21-27, an additional and more extensive search was carried out in three of the major "Bad Land" areas of the

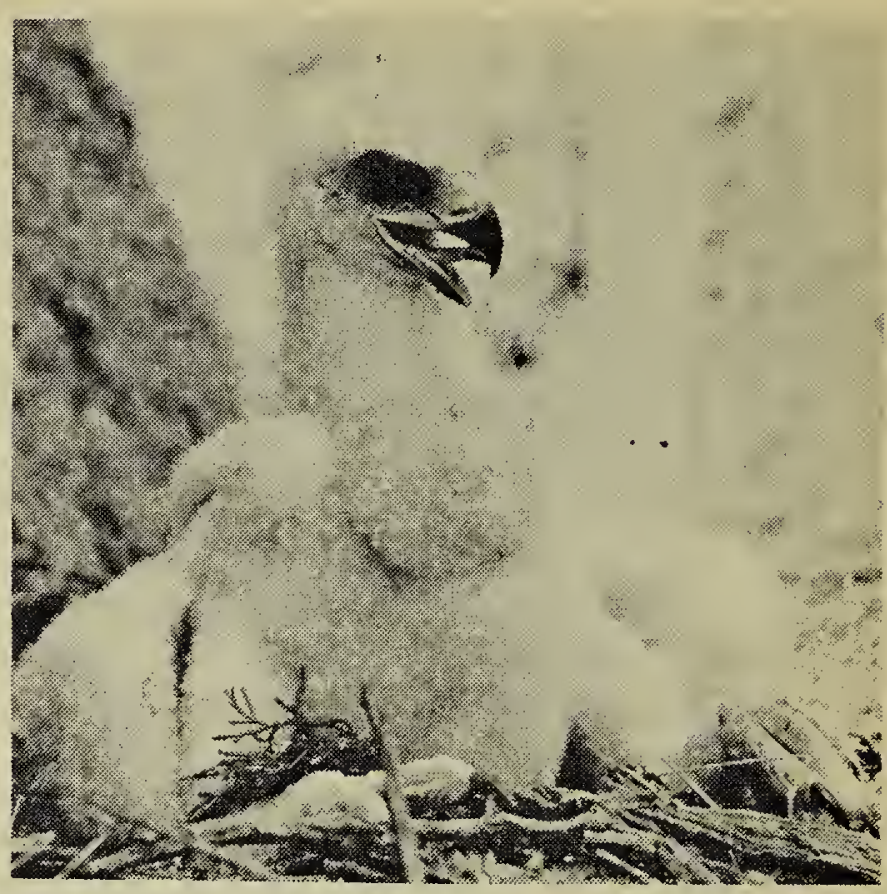

Photo by $R$. W. Fyfe

Fig. 2. Eaglet at $31 / 2$ weeks of age.

province. This resulted in three additional active aeries being located: another nest in the South Saskatchewan River Valley, one in the Big. Muddy Valley, and one in the Killdeer Badlands. This brings the total of reported nests for Saskatchewan to six, with four known to be active during the present year.

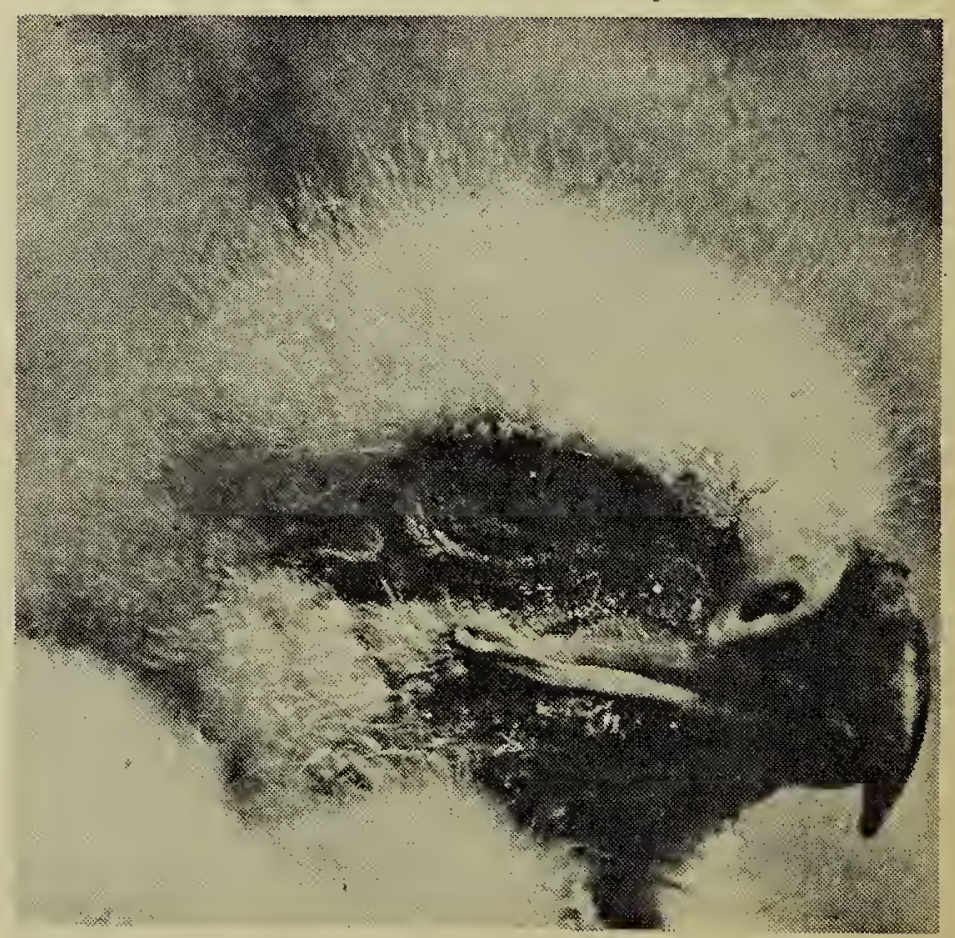

Photo by F.W. Lahrman

Fig. 3. Portrait of eaglet at one month. 


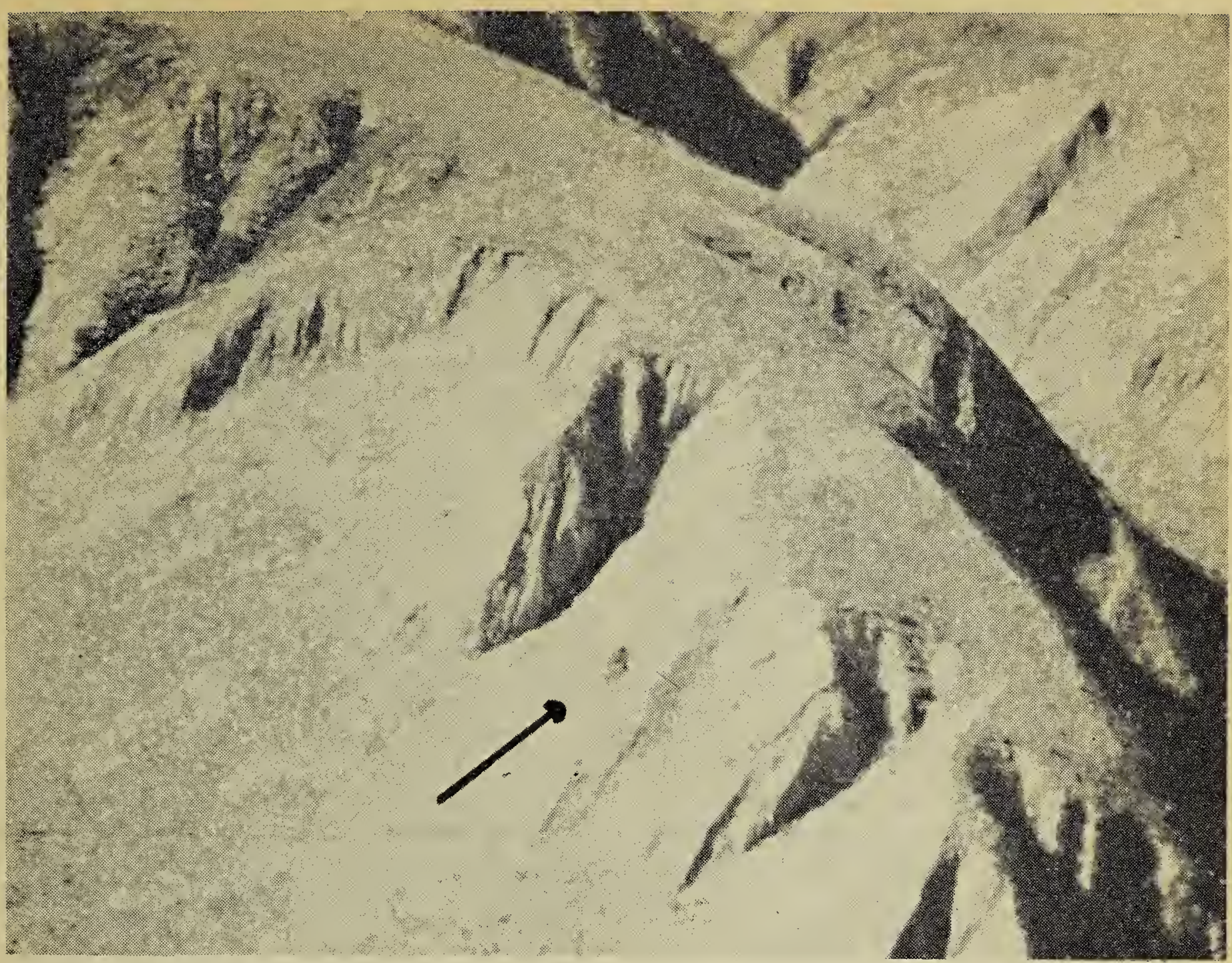

Photo by R. W. Fyfe

Fig. 4. Aerial photo of Golden Eagle's nest on north bank of Snakebite Coulee.

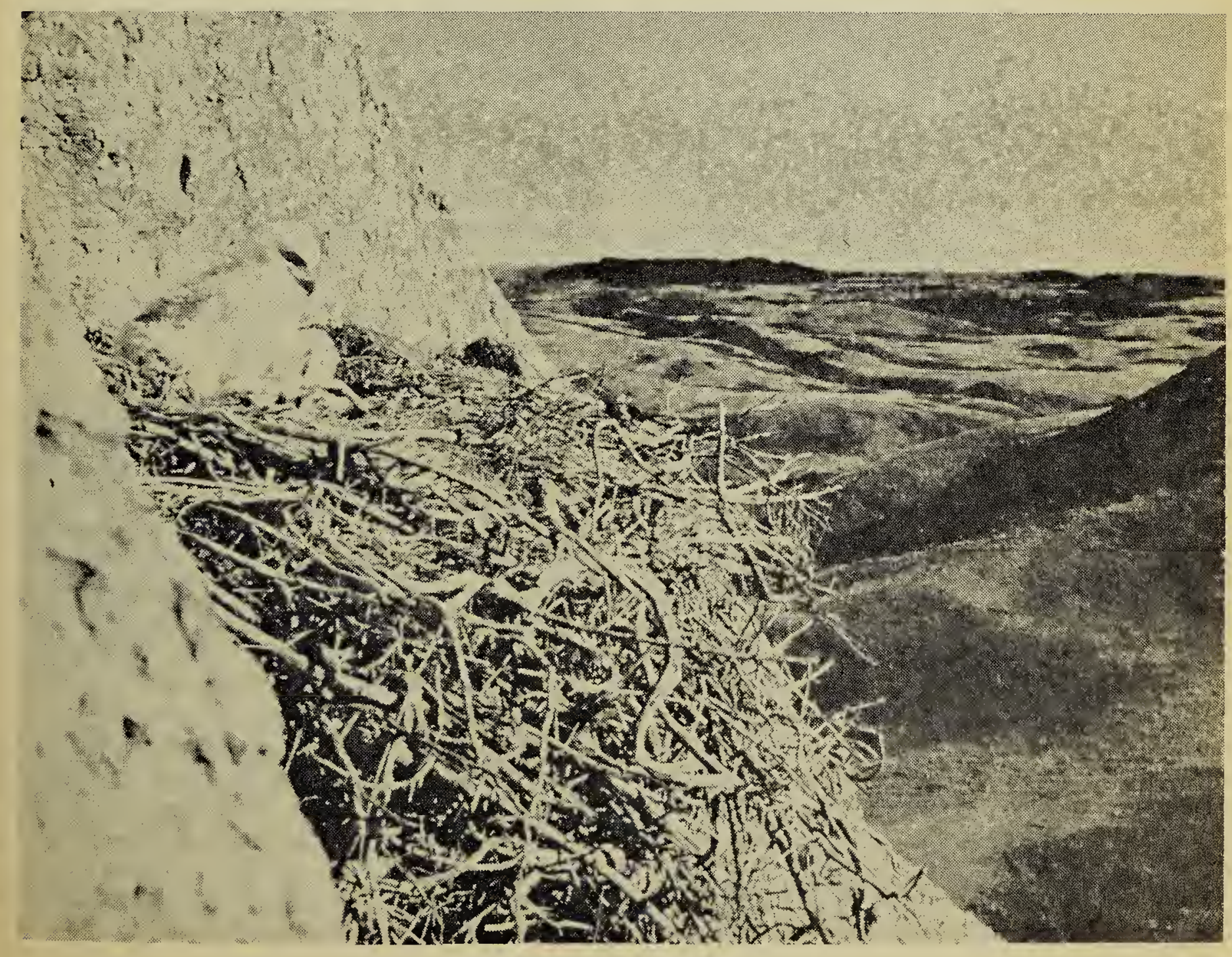

Photo by F. W. Lahrman

Fig. 5. The eagle's aerie overlooking Snakebite Coulee. 